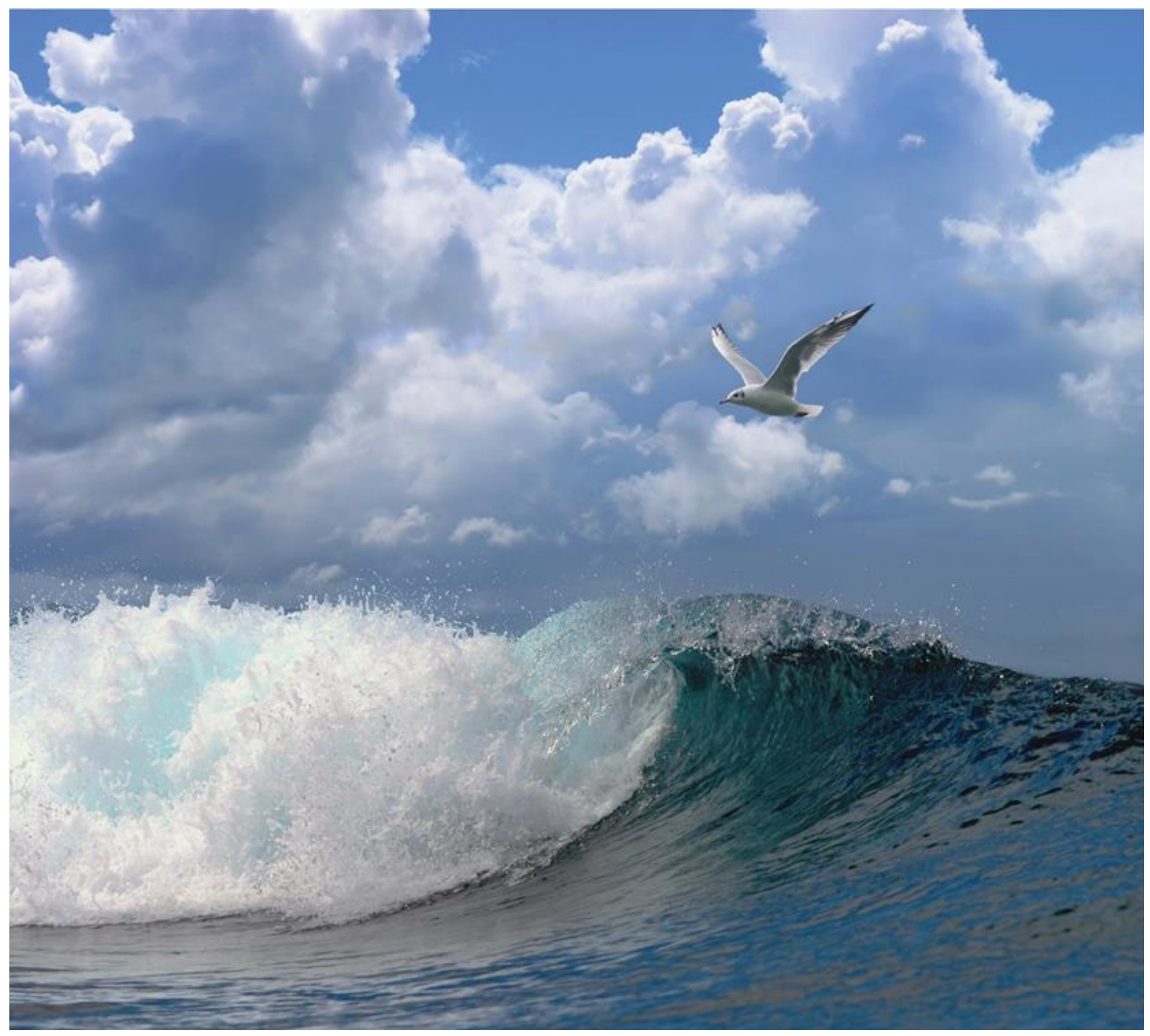

Pilot field study: observations from a fixed platform on occurrence and behaviour of common guillemots and other seabirds in offshore wind farm Luchterduinen 


\section{Pilot field study: observations from a fixed platform on occurrence and behaviour of common guillemots and other seabirds in offshore wind farm Luchterduinen}

(WOZEP Birds-2)

Author(s): $\quad$ Mardik F. Leopold \& Hans J.P. Verdaat

Publication date: 24 September 2018 
Leopold M.F. \& Verdaat H.J.P., 2018. Pilot field study: observations from a fixed platform on occurrence and behaviour of common guillemots and other seabirds in offshore wind farm Luchterduinen (WOZEP Birds-2). Wageningen, Wageningen Marine Research (University \& Research centre), Wageningen Marine Research report C068/18. 27 pp.

Keywords: Offshore wind farm, guillemot, gannet, displacement, behaviour, habituation

Client: $\quad$ Dir. Veiligheid en Watergebruik. Afd. Waterkwaliteit en Natuurbeheer

Rijkswaterstaat Water Verkeer en Leefomgeving

T.a.v.: , Ingeborg van Splunder

Zuiderwagenplein 2

8224 AD Lelystad

This report can be downloaded for free from https://doi.org/10.18174/460411

Wageningen Marine Research provides no printed copies of reports

Wageningen Marine Research is ISO 9001:2008 certified.

(C) 2016 Wageningen Marine Research Wageningen UR

Wageningen Marine Research The Management of Wageningen Marine Research is not responsible for resulting institute of Stichting Wageningen damage, as well as for damage resulting from the application of results or Research is registered in the Dutch research obtained by Wageningen Marine Research, its clients or any claims traderecord $\mathrm{nr}$. 09098104, related to the application of information found within its research. This report BTW nr. NL 806511618 has been made on the request of the client and is wholly the client's property. This report may not be reproduced and/or published partially or in its entirety without the express written consent of the client. 


\section{Contents}

$\begin{array}{lr}\text { Summary } & 4\end{array}$

1 Introduction $\quad 5$

2 Assignment $\quad 7$

$\begin{array}{llc}3 & \text { Materials and Methods } & 8\end{array}$

3.1 Training and organisation $\quad 8$

$\begin{array}{lll}3.2 & \text { Selecting an offshore wind farm } & 8\end{array}$

3.3 Transportation to the wind farm transfer to the turbines 8

$\begin{array}{ll}3.4 & \text { Observation methods }\end{array}$

4 Results $r$

4.1 Narrative day 1: 9 January $2018 \quad 11$

4.2 Narrative day 2: 10 January 2018

$5 \quad$ Preliminary impressions and recommendations $\quad 17$

6 Recommendations $r \begin{aligned} & 19\end{aligned}$

$\begin{array}{llr}7 & \text { Towards a protocol for future observations } & 21\end{array}$

$8 \quad$ Quality Assurance $\quad 23$

$\begin{array}{lr}\text { References } & 24\end{array}$

$\begin{array}{lr}\text { Justification } & 26\end{array}$ 


\section{Summary}

Two marine ornithologists spent two days watching seabird behaviour from a fixed platform at the periphery of offshore wind farm Luchterduinen, The Netherlands, in January 2018. The aim of this study was to assess whether meaningful observations could be made from a non-moving platform, that was part of the wind farm scenery, i.e., one of the turbine foundations. On each observation day, a turbine was selected that was located at the wind farm perimeter, that offered views both of the interior of the wind farm and to waters just outside the wind farm. Earlier studies of seabirds in offshore wind farms have shown that many species tend to avoid wind farms, but also that some individuals, of most species, do enter. However, as these studies are typically conducted from moving platforms (ships or aircraft), it is not known how birds behave within a wind farm perimeter. Birds that find themselves between moving turbines might be intimidated. This might impair their normal feeding behaviour at sea, if the birds would be overly watchful, or mainly seeking to exit the wind farm. On the other hand, birds may specifically move into a wind farm, if they can deal with the fact that turbines are present, and if feeding conditions within the wind farm are good. Such birds would be expected to show feeding behaviour, such as diving.

Seabirds may also be habituating to the presence of wind farms in their environment. In the airspace below the rotors, at the sea's surface and under water, there is no danger to seabirds from collision. Seabirds can thus safely enter and feed in offshore wind farms, and may, over the years, have learnt to exploit this new habitat. Therefore, even though earlier studies have shown displacement of seabirds away from offshore wind farms, this may no longer be the status quo as seabirds may be adapting to the new situation: a marine environment with offshore wind farms.

Two auk species, the common guillemot and the razorbill, were seen to move through the wind farm. Birds were seen here both flying and swimming, and diving (presumably for food) was commonly seen. Northern gannets were also commonly seen within wind farm perimeters, but only flying: not swimming or diving. We observed bird behaviour during only two days, in a relatively new wind farm not visited by us earlier, while using different methods of observing seabirds, as compared to earlier $\mathrm{T}-0$ and $\mathrm{T}-1$ studies nearby offshore wind farms. Acknowledging these methodological limitations, seabird presence in the wind farm seemed considerably higher than observed during the earlier T-0 and T-1 (personal observations) periods. This might suggest that these birds (both auks and gannets) are habituating to the wind farms in their environment.

Based on this pilot study of only two days of observations in only one season, it is fair to conclude that meaningful behavioural observations can be made from the turbine foundations and that the suggested process of habituation can be followed. It is suggested to conduct more such observations and to do so both from peripheral turbines and from turbines deeper into the wind farm. 


\section{Introduction}

Offshore wind farms in the North Sea constitute a booming business. In many parts of the North Sea wind farms are now operational and many more sites will be built up in the near future (Leopold et al. 2014). Seabirds will need to adjust to this change of their marine environment, either by avoiding wind farms, or by learning to exploit them. A growing number of studies has compared seabird densities within offshore wind farms to the waters around them. Generally, these studies have shown that many species of seabirds tend to be displaced from offshore wind farms. Seabird densities in the wind farms are generally lower than might be expected based on densities in surrounding waters (Dierschke \& Garthe 2006; Furness et al. 2013; Krijgsveld 2014; Dierschke et al. 2016). However, individuals of even strongly avoiding species might enter a wind farm occasionally; some species show little or no displacement and at least one species, the great cormorant, is clearly attracted to offshore wind farms (Leopold et al. 2013).

Assessing (differences in) seabird densities in offshore wind farms and surrounding waters has been common practice in wind farms across the North Sea. However, the mere notion that seabird densities differ (or do not differ) between the wind farm's footprint and the surrounding waters tells us little of seabird ecology within the wind farm. Birds may enter a wind farm accidentally and, once inside, may move away from it quickly. Alternatively, birds may specifically seek out a wind farm to rest (if, for instance, shipping intensity is relatively low here, or use the turbine foundations or other structures to rest), or they may come in to exploit new feeding opportunities (Vanermen et al. 2014). It is thus important to learn more about the behaviour of seabirds within offshore wind farms. Resting may be an important part of the ecology of seabirds, as resting birds conserve energy, may digest food obtained earlier, socialise with conspecifics, or watch the surroundings for e.g., feeding opportunities. There is growing evidence that turbine foundations and other wind farm-related structures such as the meteo mast in wind farm OWEZ or the Offshore High Voltage Stations (OHVS) in other wind farms are frequently used for resting by great cormorants and various species of large gulls (Leopold \& Verdaat 2018).

Another matter that needs attention is habituation. Birds are obviously adaptive animals that can learn to exploit new possibilities. Wind farms may offer predictable resources such as fishes that are associated with turbine foundations and the protective boulders for scour protection at the sea floor. If such resources are sufficiently profitable for feeding, birds might be learning to utilise these and hence, densities of seabirds within wind farms would be expected to increase, as already suggested by Krijgsveld et al. (2011) and by Vanermen et al. (2011). Should this be the case, earlier assessments of the amount of habitat loss for seabirds from offshore wind farms (e.g., Leopold et al. 2014) would need adjustment. Considering this further, certain seabirds might become "winners" and others, that keep shying away from offshore wind farms, may become "losers" and as a result, the outcome of competition between seabirds, both within and between species, may shift.

Considering these -as yet, still hypothetical- possibilities and the large number of present and future offshore wind farms, it is important to conduct studies of seabird behaviour and seabird ecology within offshore wind farms. Most methods used previously to study seabirds in relation to wind farms are unlikely to be of much use for this, however. Seabird behaviour can hardly be studied from passing ships or aircraft as the time for behavioural observations is short while these moving platforms themselves may disturb the very behaviours needing study. Radar studies provide more behavioural details, for instance on flight paths of birds that fly through an offshore wind farm. Until present, such studies mainly aimed to refine collision probability modelling by collecting more data on how birds avoid collision by taking evasive action (Krijgsveld et al. 2011; Krijgsveld 2014). Visual observers of Bureau Waardenburg, conducting these studies noted some seabird behavioural traits in the margin of these radar studies: they noted, for instance, that gulls seemed undisturbed by the presence of the turbines and that they sometimes even foraged in the wind farm (Krijgsveld et al. 2011). Foraging has also been observed (in passing) during seabirds at sea counts from ships by e.g., Leopold et al. (2009, 
2011) and Vanermen et al. (2014): great cormorants, gulls, terns and auks have been seen feeding in offshore wind farms occasionally. Great cormorants were probably the first birds to fully exploit wind farms at sea, as these offered both feeding and resting (wing drying) opportunities for this species. Other species may now be expected to follow, if feeding conditions are sufficiently good within offshore wind farms and if they can overcome initial reservations against entering such sites. Studies specifically targeted on the feeding ecology of seabirds inside wind farms are therefore needed to gain more insight if and how seabirds can exploit this new habitat at sea (Dierschke et al. 2016). 


\section{Assignment}

In this report we describe the results of a first pilot study in which we watched occurrence and behaviour of seabirds moving through offshore wind farm Luchterduinen in winter. The following questions were addressed:

1. Is it possible to conduct meaningful observations on seabirds from a fixed observation platform situated at the periphery of an offshore wind farm?

2. Is it possible to design a first draft of a protocol for systematic observations of seabird behaviour at sea from fixed platforms?

The target species of this study was the common guillemot, but all seabirds within view were recorded. A fixed observation platform was chosen because it was expected that observers working from an already existing platform, rather than from a passing ship, would not disturb behaviour of birds in the vicinity.

3. Can the obtained results be evaluated to comment on the amount of data (time spent in the field, number of different locations) that would be needed for more rigorous statistical analyses? (note that research questions for such an analysis would need to be formulated first).

4. What are the logistical issues that need to be solved for conducting such observations from turbine foundations?

5. Can useful results be obtained from such a study against reasonable costs?

Rijkswaterstaat, the commissioner of this work, asked that two days of fieldwork should be conducted in late autumn or winter, in an offshore wind farm off the Dutch mainland coast. Currently, three wind farms are in operation here: Offshore Wind farm Egmond aan Zee (OWEZ), Prinses Amalia Wind farm (PAWP) and Wind farm Eneco Luchterduinen (LUD). Permission to board a turbine foundation was needed from the wind farm owner and, as the target species for the study was the common guillemot, good numbers of these birds should be present. Permission to work in the wind farm could only be obtained for trained (in safety issues) observers and acquiring the certificates needed to work in a wind farm were therefore mandatory for this work. 


\section{$3 \quad$ Materials and Methods}

\subsection{Training and organisation}

Untrained personnel will not get permission to board an offshore turbine foundation, given the rules and regulations that apply to these facilities. Offshore wind turbines are potentially harmful, with their fast moving rotors and high voltages. The offshore environment is also potentially dangerous and getting onto a turbine foundation involves a transfer from a ship to the foundation and climbing up to ca $17 \mathrm{~m}$ above sea level. Risks of falling, hypothermia and drowning must thus be mitigated. In addition, in case of quickly deteriorating weather or ship failure, evacuation from the turbine may be difficult, while in case of an on-board injury or other calamity, the seabird observers can, at least initially, only rely upon each other. Therefore, it was required that two observers would get onto the turbine for the observations (so that they could help each other in case of emergency) and that they would be trained in first aid, working at height, safety and survival at sea and firefighting, and that they would be physically fit. Certified certificates were required for all of the above. Further, the observer were required to wear (and know how to use) "PPE": Personal Protective Equipment, such as safety footwear, gloves, helmet, goggles, survival suit and life vest, and climbing gear for mounting the foundation. Two WMR ornithologists that were assigned to this job received all the necessary training and got the required health and safety certificates to be qualified to do this work.

\subsection{Selecting an offshore wind farm}

The only legal way to get access to a turbine in a Dutch offshore wind farm is by joining one of the vessels that regularly go on-site for maintenance. This work is done only during good weather (not too much wind, wave height less than ca $1 \mathrm{~m}$ ) and such conditions are relatively rare in autumn and winter. The work thus required a combination of a permit to work, maintenance being done, good weather and available seats on a transfer vessel. And, obviously, good numbers of guillemots should reasonably be expected to be present in and around the wind farm of choice. ENECO, the owner of two of the three wind farms off the Dutch mainland coast, agreed to give us access, provided that all health and safety certificates could be shown in advance, and that a work method statement (WMS) would be written and approved by the company. This WMS (Verdaat \& Leopold 2017) was written, checked, amended and finally approved. Guillemot presence in time and space was checked from the latest published at-sea surveys in the area (Skov et al. 2016) and after consulting with ENECO and RWS it was decided to select LUD for the work, in January 2018, weather and maintenance permitting. This choice was not straightforward. Most maintenance in the first months of 2018 was planned for PAWP, but guillemot densities were supposedly much lower there, than in LUD. Much more maintenance was planned later in the year, but by that time the guillemots would have left. The possibility of arranging other means of transport were considered but deemed too expensive and unpractical as in any case supervision from an ENECO safety officer would be required.

\subsection{Transportation to the wind farm transfer to the turbines}

The WMS stated, that the observers would travel from the port of IJmuiden to LUD and back, with the maintenance vessel Offshore West Hinder, one of the ships run by Vestas for work in LUD and PAWP. Responsibility for the safety of the two observers was thus transferred to Vestas and a communication plan was set up to inform both parties, Vestas and WMR, CC RWS and Eneco, on emerging possibilities 
for a visit. Vestas agreed to inform WMR on upcoming maintenance trips to LUD. One day before departure from IJmuiden Vestas and WMR would have to agree on which turbine would be visited by the bird observers (mandatory for the safety plan); and that the observers would arrive in IJmuiden, at the Vestas office, early, in order to have a toolbox meeting with the trip leader. In that toolbox, the whole procedure to going to the vessel, boarding it, sailing to LUD, transferring to the turbine, climbing up to the observation platform, opening the turbine door and turbine entry, staying on the turbine, contact with the vessel and the reverse trip back to port, was reviewed. From entering the office, the trip team leader would be responsible for all safety issues, but he would not join the observers during the work at the turbine. The ship would drop off the observers at the turbine and sail away to do work elsewhere in LUD, and would not come close until shortly before departure, leaving the immediate area around the turbine undisturbed. Ship and observers maintained contact by VHF radios. The team leader would operate the crane on board of the turbine, to lift (on and off) the equipment used by the observers that would be packed safely in certified lifting bags. Finally, it was agreed that Vestas personnel on board the ship would guide the observers safely onto and off the turbine base.

\subsection{Observation methods}

On two successive days, 9 and 10 January 2018, seabirds were observed from a turbine foundation situated at the periphery of offshore wind farm Luchterduinen. On the first day turbine \#31 served as the observation platform (GPS (WGS 84): $52^{\circ} 24^{\prime} 40.680^{\prime \prime} \mathrm{N}, 04^{\circ} 11^{\prime} 20.120^{\prime \prime} \mathrm{E}$ ); on the second observation day turbine \#18 (52 $\left.24^{\prime} 14.642^{\prime \prime} \mathrm{N}, 04^{\circ} 08^{\prime} 10.818^{\prime \prime} \mathrm{E}\right)$ was selected. These turbines are situated along the eastern and western side of this wind farm, respectively (Figure 1 ).

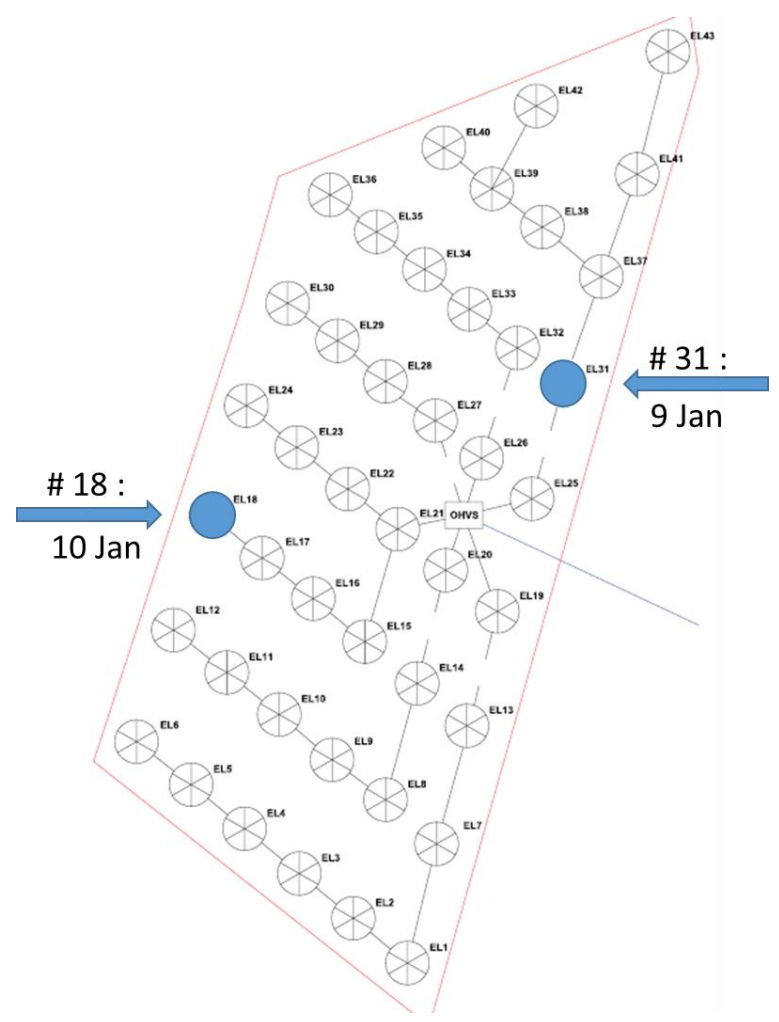

Figure 3.1 The lay-out of offshore wind farm Luchterduinen (LUD). The two turbines that were used for the observations of seabirds within the wind farm and just outside it, are highlighted. This wind farm has 43 turbines (numbered circles) that are connected to each other and to the Offshore High Voltage Station OHVS by underground cables (grey lines). The LUD turbines are Vestas V112 (3 MW), with a hub height of $81 \mathrm{~m}$, blade length of $55 \mathrm{~m}$ and a platform at ca. $17 \mathrm{~m}$ above sea level (https://www.eneco.nl/over-ons/projecten/wind farm-luchterduinen/). 
Departure from port (IJmuiden) was early on both observation days, in order to have a full working day at sea for maintenance work. After arrival at the pre-selected observation turbine, the team leader and the two observers were transferred to the turbine one by one, secured themselves using their climbing gear and climbed 17 meters to the observation platform. The turbine door was opened to provide the observers with a dry and sheltered room to change and store provisions and other materials; this room also provided safety (shelter) in case of bad weather or (worst case scenario) a prolonged overnight stay. The team leader hoisted all equipment up to the platform (and lowered this onto the ship again at the end of each day). The turbine has a diameter of circa $5 \mathrm{~m}$ at the elevation of the observation platform and always provided shelter from wind and rain at one side. Observing seabirds from the non-sheltered side, against wind and at times (light) rain, proved difficult; making observations down wind was no problem. Seabirds were mostly detected with the naked eye and further watched through $10 \mathrm{x}$ magnifying binoculars and an up to 70x (zoom) telescope on a tripod. Both observers could sit down in a chair; observations were noted down on paper. The chairs and the tripod were secured to the platform by safety lines, preventing these to be blown away and falling down into the sea. The observers themselves were safe from falling down, as the observation platform had safety railings all around.

Day 1 started with a familiarization round. Observation conditions into all directions were assessed and judged to which distances seabirds could be meaningfully observed. We estimated that this would not be feasible beyond the nearest (adjoining) turbines. Distances to these turbines were measured by a laser range finder, as: from turbine \#31 to the turbine to our left (\# 25; looking into the wind farm; see Figure 1): $816 \mathrm{~m}$; to the turbine diagonally-left (\#26): $956 \mathrm{~m}$; to the turbine right in front of us (\#32): $532 \mathrm{~m}$; to the turbine diagonally-right (\#38): $1055 \mathrm{~m}$; to the turbine to our right (\#37) 808 $\mathrm{m}$. On day 2, looking out from turbine \#18 these distances were, : $800 \mathrm{~m}, 970 \mathrm{~m}, 580 \mathrm{~m}, 1030 \mathrm{~m}$ and $830 \mathrm{~m}$ (from left to right). After a few preliminary observations that were used to assess how well birds could be watched at various distances, it was decided to concentrate effort on the area within the semi-circle of neighbouring turbines (and on a similarly sized area at the other side of the observation turbine, outside the wind farm). However, the observers mostly watched the waters that were within reach at the wind farm side of the observation turbine, particularly on day 1 , when this was down wind. Watching for birds outside the wind farm required walking around the turbine, and into the wind ( $4 \mathrm{Bft}$ ) and this seriously hampered observations on that side. When birds were seen, the known distances to adjacent turbines were used to estimate the distance between the bird and the observers, or to estimate how far birds got into the wind farm from its periphery.

As it was not known, at first, what kind of data could be collected effectively, and because bird densities within the wind farm appeared to be rather low, it was decided to note presence and behaviour of all birds that could be picked up: effectively this means all birds that moved through the area between the observation turbine and the neighbouring turbines (and a similar area at the other side of the turbine, just outside the wind farm). Observations were noted in 30 minute blocks, without pauses in between. Note that the area that could be watched "outside" the wind farms was in fact directly adjacent to it, and unlikely to be undisturbed. The value of observations within this "reference area outside the wind farm" would thus be limited. Systematic observations on day 1 commenced at 10:00 local winter time (9:00 utc). Preliminary observations before that time included one of a northern gannet (further: gannet) flying through the wind farm and one of a common guillemot (further: guillemot) in full summer (nuptial) plumage (hence: a likely adult) that came flying towards the observation turbine from deeper inside the wind farm. This bird passed the observation turbine and continued flying into the same direction, away from the wind farm.

Because the assignment of this pilot study was to concentrate efforts on collecting data on guillemots, and if possible on razorbills, these two species got special scrutiny and the observers concentrated on detecting birds swimming on the water's surface. However all other seabirds other than gulls and great cormorants (further: cormorants), and all marine mammals were also noted. Gulls and cormorants habitually use turbines for resting, so the wind farms off the Dutch coast are now known parts of their at sea habitat (Leopold \& Verdaat 2018). These birds were only noted if they interacted with auks (guillemots and/or razorbills) or with turbines. 


\section{$4 \quad$ Results}

\subsection{Narrative day 1: 9 January 2018}

Conditions: wind $4 \mathrm{Bft}$, completely overcast but no rain, visibility good ( $>5 \mathrm{~km}$ ). Observation period: 10:00- 14:10 hrs.

Preliminary observations: before formal observations started, we noted several gannets flying through the wind farm: at 09:44 two adults; at 09:46 an immature bird ("plumage 4"); at 09:54 another immature bird (exact plumage stage not noted). At 09:57 we see a guillemot in summer plumage flying from the wind farm to the outside. Systematic observations commenced at: 10:00 (in back to back blocks of half an hour).

From 10:00:

Gannet adult flies through the wind farm.

Guillemot in winter plumage (W) swims at ca 300 m outside the wind farm, is alert, as it swims with a "long" neck and does not dive. Wind and waves push the bird closer to the wind farm periphery, but the bird flies away before it crosses the line between two outer turbines and so avoids drifting into the wind farm. This would seem a clear case of avoidance.

Guillemot (W) flies through the wind farm.

Harbour porpoise: two animals swimming together enter the wind farm and disappear from sight. Gannet adult flies through the wind farm. We can see no signs of agitation or of increased awareness. Gannet adult flies through the wind farm.

From 10:30:

Guillemot in summer plumage ( $S$; see explanation in the text box below) flies from the open sea outside the wind farm into the wind farm and continues flying through the wind farm.

Guillemot (W) flies from the open sea outside the wind farm into the wind farm and continues flying through the wind farm.

Razorbill (W): two birds are foraging (diving) at the periphery of the wind farm (right between two of the outer turbines). The birds dive repeatedly, staying under water for around 30 seconds each time. They do not cross the line between the two outer turbines and seem alert when at the surface. They seem well aware of the presence of the turbines and probably see the observers watching them (they appear to be "watching back"). After a few minutes at the periphery of the wind farm, they fly off (avoidance?). Note: a clear definition of "avoidance" is lacking for this particular situation.

Feral pigeon: a tame and/or exhausted bird lands on the observation platform and stays around.

From 11:00:

Guillemot: we spot a guillemot rather deep into the wind farm through the telescope: beyond one of the neighbouring turbines. The bird spends several minutes preening its feathers, does not dive. It slowly drifts further away from us and we have to let it go in order to keep concentrating on the primary study area (between the observation turbine and the semi-circle of neighbouring turbines. Here, we spot a guillemot (S) flying low over the water through the wind farm.

From 11:30:

Gannet adult flies through the wind farm.

Guillemot (W) swims actively with the wind in its back into the wind farm, looking around, but seemingly relaxed: no long neck, sometimes spinning around leisurely. Looks down into the water while still swimming at the surface, before diving down at circa $250 \mathrm{~m}$ from the observation turbine into the wind farm. We cannot find the bird again after its dive, in the wind-swept waters. 
From 12:00:

Guillemot (S) seen swimming just outside the wind farm, at ca. 50 m "behind" the observation turbine. As the bird dives, we time its time under water with a stop watch as 1 min 30 seconds. It surfaces again well into the wind farm, at ca $250 \mathrm{~m}$ from our position. It stays at the surface for 30 seconds, dives again and is lost from sight. The bird swims and dives with the running tidal current, from the periphery into the wind farm.

Gannet: a group of three adult birds fly alongside the wind farm, with one bird within and the other two just outside the wind farm perimeter.

Razorbill: we spot two adult birds (given size, shape and coloration of their bills) in winter plumage at ca $300 \mathrm{~m}$ into the wind farm, accompanied by a kittiwake (adult, W). The razorbills seem both relaxed (preening) and alert (looking around), swimming slowly into wind and waves. After the kittiwake flies off, the razorbills start diving, at ca $250 \mathrm{~m}$ inside the wind farm. We only find them back again at the surface after 3 minutes (probably after several dives), at the wind farm's periphery. After 20 seconds at the surface they dive again and are lost from sight. As we did not see the birds fly into the location where they were first seen, they probably came from deeper into the wind farm, swimming and possibly diving.

Harbour porpoise: three animals swimming slowly (leisurely) through the wind farm. Razorbill (W) a group of four birds flies through the wind farm.

\section{Box: Summer plumage-winter plumage and ageing of auks:}

Guillemots that are in January in full summer (nuptial) plumage (or even moulting into summer plumage) may be considered adult; birds still in winter plumage can also be adult, but are more likely immatures or first winter birds. Razorbills moult into summer plumage several months later than guillemots; in January nearly all razorbills are in winter plumage so in this species plumage cannot serve as an aging tool at this time of year. However, adult razorbills have higher bills than younger birds, with a white vertical line (lacking in juveniles) and two or more vertical uncoloured groves (only visible at short range). Guillemots are thus easier aged than razorbills at this time of year, as a dark head (summer plumage) is easier seen than a white line on a razorbill's bill. A good telescope is a necessary tool to age razorbills, even at relatively close range (within a few hundred metres).

From 12:30:

No birds seen in the wind farm (or just outside).

From 13:00:

Razorbill (W) two birds fly through the wind farm.

Razorbill (W) first seen at $500 \mathrm{~m}$ distance, (= $200 \mathrm{~m}$ within the wind farm periphery), bathing and preening. It swims slowly into the wind, moving towards the wind farm's periphery, staying at the surface. Just before it is about to leave the wind farm it dives, and apparently doubles back under water, as it resurfaces after 1 minute deeper into the wind farm. It stays at the surface, drifting for 10 minutes, just inside the wind farm. Next, it dives again (40 s) and after it resurfaces keeps at the surface, drifting slowly out of sight, but remaining inside the wind farm for as long as we can follow its drift.

Guillemot (W) at ca $700 \mathrm{~m}$ to our side, swimming in the wind farm, passing a (neighbouring) peripheral turbine at ca $100 \mathrm{~m}$. Swims steadily on until it reaches the wind farm's periphery, staying at the surface at all times. Swims by a (swimming) common gull at close range after it has crossed the wind farm's periphery, ignoring it.

Razorbill (W) flies from the outside into the wind farm, and on through the wind farm.

Razorbill (W) flies from the inside of the wind farm to its outside.

Gannet: a group of four adults flies through the wind farm.

Razorbill (W) seen swimming $700 \mathrm{~m}$ into the wind farm. It spots another razorbill swimming in the wind farm, some $200 \mathrm{~m}$ away, and the two birds swim towards each other and join each other.

Guillemot (W) flies towards the two razorbills (inside the wind farm) lands next to them and immediately dives. Stays under for only 17 seconds (shallow dive). The first razorbill dives two seconds after the guillemot dives and surfaces after 15 seconds together with the guillemot. The 
guillemot dives again and is lost from sight. The two razorbills dive with the guillemot, and resurface after 40 seconds (the guillemot is not seen resurfacing), recuperate for 10 seconds, dive again (30 s), and again (20 s), and again, but are now lost from sight. A (or the same) guillemot surfaces at 100 $\mathrm{m}$ from the observation turbine. We find the razorbills back at a much larger distance, some $200 \mathrm{~m}$ from where they last dived, and well separated from the (?) guillemot.

From 13:30:

We keep following the guillemot at close range. It swims to the wind farm periphery, takes off and flies away from the wind farm).

The two razorbills keep on diving inside the wind farm: $25 \mathrm{~s}, 30 \mathrm{~s}, 45 \mathrm{~s}$.

A third razorbill is seen, swimming slowly, minutes long just (ca. $100 \mathrm{~m}$ ) outside the wind farm. This bird too starts diving (just outside the wind farm): $49 \mathrm{~s}, 50 \mathrm{~s}, 55 \mathrm{~s}$, and once again but is not seen resurfacing.

Razorbill: a group of 8 birds flies through the wind farm.

Gannet (adult) flies along the periphery of the wind farm (along its outside).

Gannet (adult) flies straight through the wind farm: from one side of the wind farm, across, to exit at the far side.

From 14:00:

Razorbill (W): two birds are spotted swimming just within the wind farm perimeter and start to dive. We see one of the birds resurface after 1 minute, 15 seconds (we may have missed an earlier resurfacing) just outside the wind farm. The second bird is not seen again.

Razorbill (W): another bird is seen swimming at a considerable distance from the earlier two, $500 \mathrm{~m}$ into the wind farm. As only one of the former two was found resurfacing, this may be the second bird. If so, it has moved over a considerable distance into the wind farm from its initial dive at the perimeter.

Guillemot (W) swims in the wind farm, $700 \mathrm{~m}$ from its perimeter.

Razorbill (W): we spot two birds right $(<50 \mathrm{~m})$ below our observation turbine. They dive $(43 \mathrm{~s})$ and resurface $50 \mathrm{~m}$ outside the wind farm, and dive again (34 s).

At 14:10 we have to end observations, as the ship is coming to get us.

\subsection{Narrative day 2: 10 January 2018}

Start of the observations at 09:30. Weather conditions: wind $3 \mathrm{Bft}$, heavily overcast grey sky, visibility ca. $3 \mathrm{~km}$ (improving slightly during the day, as it becomes lighter). Regularly drizzle or light rain, but in the shelter of the turbine this does not hamper the observations (though on the other side, evidently, it does).

From 09:30:

Gannet: two adult birds fly through the wind farm.

Guillemot (S) swims just outside the wind farm, dives and is lost from sight.

Razorbill (W): three birds continuously diving just outside the wind farm: ca. $50 \mathrm{~s} ; 55 \mathrm{~s} ; 53 \mathrm{~s} ; 50 \mathrm{~s}$; $45 s ; 46 s ; 47 s ; 35 s ; 29 s$ and at least once more (not seen surfacing again). After the fifth dive in this recorded series of dives, a fourth razorbill that flies by, joins the groups to dive with the already diving birds. An adult kittiwake briefly joins the diving razorbills by alighting on the water next to them, but does not further interact and quickly flies off again. Between dives, the razorbills recuperate at the surface for 10-30 seconds.

Guillemot (S) swims outside the wind farm and dives. It resurfaces after 1 minute, 16 seconds, 200 $\mathrm{m}$ from the location where it started its dive (still outside the wind farm); looks around, flaps its wings, preens, flies off and lands again, all just outside the wind farm.

Cormorant: A group of five birds was resting on turbine \# 24, and now flies off and away. 
From 10:00:

Gannet: One single bird after the other (six in total) flies through the wind farm at rather large distances ( $>1 \mathrm{~km}$ ) from the observation turbine; all birds appear to be adults.

Guillemot (W) flies through the wind farm.

Razorbill (moulting towards summer plumage) swimming and preening, just outside the wind farm.

Harbour porpoise: swims leisurely just within the wind farm perimeter.

A mixed group of four razorbills and one guillemot fly through the wind farm. We follow their flight with our binoculars: they land centrally in the wind farm, but are lost on the water.

Cormorant flies down from a turbine, lands $10 \mathrm{~m}$ from its base and dives immediately. Not seen resurfacing due to large distance.

Guillemot flies through the wind farm.

From 10:30:

A multitude of single gannets flies through the wind farm: subsequently an adult bird; an immature; adult; immature (plumage 4); immature (plumage 3); adult. One more gannet (adult) flies along the wind farm perimeter, keeping to its outside.

Guillemot (W): we spot a bird that swims into the wind farm. Once inside, it takes off and flies away, leaving the wind farm (avoidance?).

Razorbill (W): just outside the wind farm, swimming. Dives (40 s), $10 \mathrm{~s}$ at the surface, dives again and is lost from sight.

Guillemot (W): two birds flying together, through the wind farm.

Northern lapwing: a group of 10 birds flies through the wind farm.

Harbour porpoise: swims from the outside into the wind farm. Some minutes before this sighting, we briefly saw a dark "shadow" moving under water close to turbine \# 24. Possibly this too was a harbour porpoise (or the same?) as we never saw anything surface there, which lessens the possibilities of a seal or cormorant, but at a distance of $800 \mathrm{~m}$ this remained unconfirmed.

From 11:00:

Guillemot (plumage not properly seen) flies through the wind farm.

Guillemot: two birds, one in summer and one in winter plumage, swimming just outside the wind farm. W flies off and away, S remains, looking around. W alights on the water again, still outside the wind farm, dives, and is lost from sight.

Guillemot: flies through the wind farm.

Harbour porpoise: swims through the wind farm. This animal is clearly smaller than the previous one. After a few minutes, the porpoise leaves the wind farm (still swimming slowly and steadily, not racing) between turbines 10 and 24 .

From 11:30:

Razorbill (W): two birds diving together in the wind farm, kept company (at the surface) by an adult kittiwake. The razorbills fist make three quick, short (and therefore shallow) dives, lasting 10-15 s. Next they alternate slightly longer and shorter dives, $28 \mathrm{~s} ; 16 \mathrm{~s} ; 10 \mathrm{~s} ; 6 \mathrm{~s} ; 5 \mathrm{~s} ; 10 \mathrm{~s} ; 21 \mathrm{~s} ; 26 \mathrm{~s}$.

A guillemot (W) and also dives: $20 \mathrm{~s} ; 46 \mathrm{~s}$.

The diving group slowly exits the wind farm. Once outside, the guillemot dives once more (23 s) one of the razorbills as well, before the birds are lost from sight.

From 12:00

Guillemot flies through the wind farm.

From 12:30:

Harbour porpoise: a small animal (same one as seen earlier?) swims through the wind farm, at $<100 \mathrm{~m}$ from the observation turbine. The animal swims straight towards the tidal wake behind the turbine foundation and dives.

Gannet: an adult bird, followed immediately by a second adult, flies through the wind farm.

Harbour porpoise: 25 minutes after the previous porpoise sighting, we see again a small animal swimming in the wind farm, now at 200 metres from the observation turbine. The porpoise shows the same behaviour as seen before, and follows the same track. Possibly, this is a "resident" harbour 
porpoise that is staying for some time in the vicinity of this turbine, foraging around its base or in its tidal wake.

From 13:00:

Harbour porpoise: 10 minutes after the previous sighting again a small animal close by, showing the same behaviour.

Razorbill (W): two birds swimming and diving just outside the wind farm: $43 \mathrm{~s} ; 49 \mathrm{~s}$; and once more (not seen again, surfacing). A few minutes later we briefly see them again before they dive again and this was the last we have seen of these two birds.

Guillemot: flies through the wind farm.

Gannet: flies along the perimeter of the wind farm, just inside its perimeter.

From 13:30:

Guillemot (one S and one W): flying together through the wind farm.

Red-throated diver (W) flying, low over the water, straight through the wind farm.

Gannet (late immature, plumage 5) flies through the wind farm.

Razorbill (W): two birds preening for a long time, just outside the wind farm.

Harbour porpoise: a group of three, swimming fast along the perimeter of the wind farm (outside), followed by group of four harbour porpoises.

Guillemot (W) flies through the wind farm.

From 14:00:

Again two harbour porpoises, 500 meter outside the wind farm, swimming into the opposite direction of the previous groups: animals doubling back? Or swimming up and down along the wind farm (barrier effect?).

Cormorant: diving (foraging at the base of turbine \# 23).

A guillemot and a razorbill, diving $100 \mathrm{~m}$ outside the wind farm (60 s under water). After resurfacing, both swim steadily into the wind and away from the wind farm.

From 14:30:

Gannet: three single adults, one after the other, followed by another bird (a plumage 5 immature) fly through the wind farm.

Razorbill (W) swims deeply in the wind farm (picked up by telescope) beyond the first neighbouring turbine ahead of us. The bird dives and is lost from sight.

From 15:00:

Guillemot (W) flies through the wind farm.

Guillemot (plumage not well seen) flies through the wind farm.

Guillemot (S) flies through the wind farm.

Brent goose: a single bird flies low through the wind farm.

Guillemot (S) flies through the wind farm, a few minutes later followed by a second (S).

Harbour porpoise: again a small (the same?) animal at less than $100 \mathrm{~m}$ from the observation turbine. By now, it appears that we are witnessing an animal exploiting the surroundings of the turbine base. The animal zig-zags a little, without moving much over the ground before it dives and disappears again.

Herring gull (adult, W) checks out the observers' platform. On the platform, we had already found remains of regurgitated herring gull pellets, full of fragments of blue mussel shells (such pellets are typical for herring gulls: see Camphuysen 2018). It appears that this gull is a specialist, that uses this platform for resting after it has fed on blue mussels in the vicinity. Blue mussels grow on turbine foundations in offshore wind farms and are available to herring gulls swimming up to the poles during low tide (pers. obs.).

From 15:30:

Razorbill (W) a group of four birds flies through the wind farm.

Guillemot (W) a group of three birds flies through the wind farm. 


\section{From 16:30:}

Grey seal: a female or immature male drifts, vertically, resting in the water, just within the wind farm perimeter, at $200 \mathrm{~m}$ from the observation turbine. It is getting dark and the ship is on its way to pick us up: observations are terminated at 16:30. 


\section{$5 \quad$ Preliminary impressions and recommendations}

Just two days of observing seabirds and seabird behaviour from a fixed platform in an offshore wind farm off the Dutch mainland coast, provided a new view on how seabirds are coping with the phenomenon of wind farms in their offshore environment. Seabirds, of several species, including species known to avoid offshore wind farms, were more or less continuously present at the site, both on the water and in the air. Feeding (diving) was not uncommon in both guillemots and razorbills and we could not see any difference in feeding behaviour inside and outside the park. Note, however that "outside" the park in this study means: no more than several hundreds of meters away from the outermost turbines. This makes it hard to ascertain differences, if present, between behaviour in the wind farm and away from it. Our view was furthermore limited to the outer section of the wind farm "one turbine deep into the site". What happens deeper into the heart of the wind farm could not be studied properly, but what could be seen from birds that flew deeper into, and through the wind farm, did not indicate drastically different behaviours. Birds were also seen diving when they landed deeper in the wind farm and birds flying through often did so on one set course, crossing the entire wind farm, exiting on the far side, rather than flying around. However, some birds were also seen flying along the wind farm's perimeter, possibly indicating reluctance to enter.

Quite unexpected, based on our earlier experience during T-0 and T-1 surveys in wind farms OWEZ and PAWP (both in the vicinity of the park now studied, LUD) was the number of gannets flying through the wind farm. Birds flew into the wind farm, and often straight through, on many occasions, without visible reluctance or hesitation. They also did this through the central parts of the wind farm, not just through the peripheral parts, as described by e.g. Krijgsveld et al. (2011). Although their flight paths were not exactly plotted, it was clear, however, that they mostly kept to the middle of the "lanes" in between two rows of turbines. On no occasion gannets were seen feeding (diving) in the wind farm, suggesting that food can still not be obtained from the wind park's footprint. Still, the next step for gannets in relation to offshore wind parks may be to start feeding here as well, as recently seen in another study (Leopold \& Verdaat 2018).

Auks, both guillemots and razorbills, have apparently already moved further along this road. On relatively many occasions, birds of both these species were seen to dive within the wind farm (as well as just outside). We could see no difference in behaviour of these birds inside and outside the wind farm. Diving birds often dived several times in succession, indicating that diving was not a panic reaction in response to them suddenly seeing a working turbine. Auks show such panic dives if an approaching ship threatens to overrun them, but such dives are quite different from the foraging dives seen in this study. On the other hand, the birds seemed well aware of the presence of the turbines, as they were sometimes seen looking around (with necks stretched), apparently eyeing our observation turbine (or the observers on it); we could not see this clearly at greater distances, e.g., next to neighbouring turbines.

Our pilot study does not provide data on relative densities of seabirds, inside and outside the wind farm. Although seabirds may be expected to adapt, over time, to new entities within their environment, the latest available study on relative densities of seabirds inside and outside LUD still shows lower densities of seabirds such as guillemots and razorbills and particularly of gannets within the LUD footprint (Skov et al. 2016), in line with earlier studies in the area (Leopold et al. 2013) and abroad (Dierschke \& Garthe 2006; Dierschke et al. 2016). Our data do show, however, that the guillemots and razorbills that enter the wind farm, are diving here and presumably obtaining food. This has important implications for how we must judge wind farm effects on seabird ecology. If birds refrain from foraging within wind farms, the entire footprint of any wind farm is lost as feeding habitat (cf. Leopold et al. 2014), no matter if birds enter the wind farm or stay out categorically. If, on the other hand, birds that are found within the wind farm forage normally, the amount of habitat loss 
would merely be the footprint of the wind farm times the reduced density of the species involved. It is also possible that seabirds (and marine mammals as well) could learn to (or are already learning to) exploit the new habitat of offshore wind farms to their advantage. Cormorants have clearly achieved this, already shortly after the first offshore wind farm was built in Dutch waters. Their densities have increased dramatically at wind farm sites and in all likelihood (although this needs to be properly established still), they are highly successful at obtaining food here. Cormorants can regularly be seen feeding directly at the base of turbines (this study and Leopold \& Verdaat 2018), but what exactly they eat here, is unknown. This could be assessed with relative ease, by studying the contents of pellets regurgitated by cormorants on sites where they rest. In fact, we found one such pellet on the observation turbine foundation. Upon inspection, this pellet was shown to hold remains (otoliths) of several gadoids (cod and bib); fish species known to school around the bases of offshore turbines (Lindeboom et al. 2011; Degraer et al. 2016).

We have seen more guillemots and razorbills in LUD than (we) expected, based on experiences from earlier ship-based surveys in Dutch offshore wind farms. Variation in local seabird densities are considerable, however, both between years and within years, and without concurrent observations well away from LUD, it is difficult to draw firm conclusions on within-wind farm densities. Still, auks were not only present in the wind farm on both observation days, they were also seen diving, and presumably feeding. With more and more offshore wind farms becoming operational in the North Sea and elsewhere, and with the existing ones being in place longer, seabirds must come into contact with (get within sight of) turbines more regularly. Auks have relatively little to fear from turbines, as they mostly move around swimming and if they fly, they mostly fly under rotor height (Garthe \& Hüppop 2004), while they may have a lot to gain from feeding in wind farms. Auks are also long-lived, with ample time to learn new skills, and may thus be expected to overcome initial fear of turbines. Our observations suggest that they may be on this track: both guillemots and razorbills are now feeding in offshore wind farms. Note, however, that we have no earlier observations, so the presumed learning curve cannot be reconstructed. Moreover, some birds may still refrain from coming into wind farms to forage, and local densities may still be depressed. It should also be noted that foraging success, i.e., numbers, sizes and species of fish could not be assessed, as birds were never seen to surface with fish: any prey caught must therefore have been swallowed under water.

Gannets, having more to fear from turbines, still seem very reluctant to feed within wind farm perimeters. However, during the two days we spent on the turbines watching them, they were flying through the wind farm regularly and without obvious constraints, other than keeping their distance from turbines while passing through: a sight that was totally unfamiliar to us from earlier experience. Still, gannets were not seen feeding (diving) in the wind farm, so effectively, still the entire site was lost as feeding habitat to this species. 


\section{Recommendations}

Our observations during this pilot study were made on just two days at sea, in only one season (in one year) and in only one offshore wind farm. Clearly, we should be very careful extrapolating these first results to other situations. LUD is a wind farm that has only become operational recently and birds may have had relatively little time to adjust to this particular wind farm. On the other hand, the birds seen most frequently, guillemots, razorbills and gannets, all come from across the North Sea, and they have probably seen other wind farms before: many guillemots and most gannets were adult birds, likely with years of experience in the North Sea. It seems likely therefore, that seabirds are moving into wind farms elsewhere as well, or will do so in due time.

The questions formulated in this report (Chapter 2) may be answered as follows:

1. It is certainly possible to conduct meaningful observations on seabird presence and behaviour from a fixed observation platform situated at the periphery of an offshore wind farm. On the other hand, observing seabirds in an undisturbed situation away from the wind farm does not seem possible, given the limited distance over which these observations can be made. Birds considered here to fly, swim or feed (just) outside the wind farm may in fact have been under the same influence from the moving rotor blades as the birds within the wind farm. Future observers should thus probably select an observation platform that gives the best views into the wind farm, given direction of wind and sun. Observing birds and bird behaviour from fixed platforms other than wind turbines might be a possibility to collect data for comparison away from offshore wind farms. Suitable platforms could be offshore oil and gas platforms, or the first transition pieces put into place for new offshore wind farms, or even anchored ships. It must be realised that any object put onto the sea's surface large enough to accommodate observers, may have the same effect as the turbines of an offshore wind farm. We have noted earlier (Leopold et al. 2011) that e.g. a concentration of stationary ships on an anchorage site had a similar displacement effect as the offshore wind farms close by.

2. The nature of our observations was largely anecdotic and this makes our data unsuitable for statistical analysis (let alone that proper research questions would have to be formulated first). Birds could mostly be followed over only limited time spans and only relatively short feeding (diving) bouts could be studied. Moreover, we could not measure foraging success: what happened under water remains hidden from observers situated well above the water's surface. We must thus think of ways to better quantify results. One way to do this (not done in this pilot study) would be to assess the proportion of birds of a given species that shows behaviour indicative of feeding (diving). Another way would be to measure total lengths of foraging bouts, but this can only be done if birds can be followed long enough (possibly under better weather conditions than experienced in this study). Such data could be collected in different wind farms, in different places within the same wind farm (more centrally, or more at the periphery) and, obviously, in the various seasons. How long observers should be watching in any one situation would then be largely dependent on how many data can be collected: this would largely depend on local densities of target species. After observers have boarded a turbine (a major logistical effort), they should probably remain there until relieved at the end of the day: switching from one turbine to another is time consuming although this could be feasible on long observation days, e.g. in summer (but note that no guillemots or razorbills would be available for study then, within Dutch wind farms). However, this type of work can also be considered valuable in spring and summer in wind farms within daily reach of their breeding colonies.

3. The logistical constraints for conducting observations from offshore wind farms are considerable. Observers much be trained and certified, and keep their certificates valid. If the same observers can be used in successive studies, obviously these investments become more profitable (less costly per day of study). Future wind farms, particularly if situated further 
offshore may be serviced by helicopter or from hotel ships, rather than by ships and this would require additional training (in the case of helicopter transport). Once on board of a turbine foundation, observers can work well and can work safely. A good relationship with wind farm owners needs to be maintained as without their permission to work in a wind farm this work cannot be done.

4. In the years to come many more offshore wind farms will become operational and the offshore habitat of seabirds will change considerably. The amount of (theoretical) ecological space for building offshore wind farms is now still large assessed by ecological modelling and may lead to restrictions on further development. If seabirds can indeed adapt to offshore wind farms and learn to forage within their perimeters, the ecological burden of the wind farms on seabirds might be less severe than currently estimated. Good field data are therefore highly valuable for future development and in this light, every effort should be made to follow developments in seabird behaviour in relation to wind farms at sea. Given that on-site observations, like described in this report, cannot evaluate relative densities of seabirds inside and outside the wind farm studied, studies such as this one are probably best combined (simultaneously, both in space and time) with classic larger-scale seabird surveys (such as: Leopold et al. 2013; Skov et al. 2016) that provide information on these relative densities. 


\section{$7 \quad$ Towards a protocol for future observations}

For future work in offshore wind farms, it is important that we realise what can be done, what cannot be done and what should be done. Birds and bird behaviour can only be observed as long as birds are on the surface, or in the air. What happens under water remains hidden, unless we can find ways to equip birds with tracking devices that log their movements and behaviour both at the surface and under water. Given that there are 1562000 guillemots wintering in the North Sea (as estimated from ship-based seabirds counts: Skov et al. 2007), chances that birds that were given trackers in breeding colonies may visit a (Dutch) wind farm, would seem remote. We know nothing on residence times of wintering guillemots at a particular site, but it could be worthwhile to invest in catching birds at sea, near offshore wind farms and equip them with trackers. As yet, observers stationed inside an offshore wind farms can:

1. Register species occurring in the wind farm,

2. Register their way of moving through: swimming or flying

3. For flying birds: register flying altitudes

4. For flying birds: register whether (or not) they show foraging behaviour (looking down, dipping, plunging)

5. For swimming birds: register diving times and recovery times, and time not spent diving/recovering

6. For birds coming up to the surface holding fish: species and sizes of fishes caught (e.g., for guillemots with chicks that are still being fed by their parents)

7. For both swimming and flying birds: track their movements through the wind farm

8. For diving birds: register distance to the nearest turbine foundation

9. Register resting birds (on turbines and other structures, most notably OHVS) and collect food remains (from regurgitated pellets of from faeces, to study seabird diets in offshore wind farms.

This could all be done at different locations within the wind farm (close to the edge or more centrally), in different seasons, and in different wind farms and a database of results, including quantitative results (amounts of time, distances, prey types) could be built. The first two point on the above list do not need further commenting.

Ad 3: flying heights: this was not part of the current study and this is more related to collision risk than to displacement. It will divert attention from birds at the surface, but if deemed important, flying birds can be assessed as (for example) flying at rotor height, or below this or above this (time at each altitude class).

Ad 4: use the behavioural coding as suggested by Camphuysen \& Garthe (2004).

Ad 5: as done in this study. Stopwatch required, but probably a tape recorder, allowing real time recording of observations would be more reliable. This needs to be done on focal birds, that are followed intensely, ignoring anything else at the time.

Ad 6: (tele lens) photography would be recommended.

Ad 7: flying birds (moving relatively fast) are probably better followed by bird radar (cf. Krijgsveld et al. 2011) than by visual observers. This was not part of this study and we will not further comment on this. Swimming birds could be followed accurately, by using a theodolite.

Ad 8: this is important for assessing if the turbine foundations themselves offer any kind of specific attraction. In that case, foraging birds would be expected to preferably dive close to the turbines. Certain fishes have been reported to concentrate around turbine foundations (Degraer et al. 2016) and feeding conditions for birds may thus be relatively good near turbines. However, not much is known about (forage) fish densities in offshore wind farms, at different distances from turbines and this would also require further study.

Ad 9: we would strongly recommend to consider studying diets of gulls and cormorants that rest in offshore wind farms, from food remains in regurgitated pellets or faeces. This, in combination with 
studying foraging behaviour of these birds in the wind farm, provides another means for collecting data on the (feeding) behaviour of seabirds in offshore wind farms. 


\section{Quality Assurance}

Wageningen Marine Research utilises an ISO 9001:2008 certified quality management system (certificate number: 187378-2015-AQ-NLD-RvA). This certificate is valid until 15 September 2018. The organisation has been certified since 27 February 2001. The certification was issued by DNV Certification B.V. 


\section{$9 \quad$ References}

Camphuysen K. 2018. De Zilvermeeuw. Uitgeverij Atlas Contact.

Camphuysen C.J. \& Garthe S. 2004. Recording foraging seabirds at sea: standardised recording and coding of foraging behaviour and multi-species foraging associations. Atlantic Seabirds 6: 123.

Degraer, S., Brabant R., Rumes B., Vigin L. (Eds.) 2016. Environmental impacts of offshore wind farms in the Belgian part of the North Sea: Environmental impact monitoring reloaded. Royal Belgian Institute of Natural Sciences, OD Natural Environment, Marine Ecology and Management Section.

Dierschke V. \& Garthe S. 2006. Literature review of offshore wind farms with regard to seabirds. In: C. Zucco, W. Wende, T. Merck, I. Köchling \& J. Köppel (eds). Ecological research on offshore wind farms: international exchange of experiences. Part B: literature review of ecological impacts. BfN-Skripten 186: 132-198.

Dierschke V., Furness R.W. \& Garthe S. 2016. Seabirds and offshore wind farms in European waters: Avoidance and attraction. Biological Conservation 202: 59-68

Furness R.W., Wade H.M. \& Masden E.A. 2013. Assessing vulnerability of marine bird populations to offshore wind farms. Journal of Environmental Management 119: 56-66.

Garthe S. \& Hüppop O. 2004. Scaling possible adverse effects of marine wind farms on seabirds: developing and applying a vulnerability index. J. Appl. Ecology 41: 724-734.

Krijgsveld K.L. 2014. Avoidance behaviour of birds around offshore wind farms. Overview of knowledge including effects of configuration. Rapport Bureau Waardenburg 13-268.

Krijgsveld K.L., Fijn R.C., Japink M., van Horssen P.W., Heunks C., Collier M.P., Poot M.J.M., Beuker D. \& Dirksen S. 2011. Effect studies Offshore Wind Farm Egmond aan Zee. Final report on fluxes, flight altitudes and behaviour of flying birds. NoordzeeWind report $\mathrm{nr}$ OWEZ_R_231_T1_20111114_flux\&flight. Rapport Bureau Waardenburg 10-219.

Leopold M. \& Verdaat H. 2018. Reacties zeevogels in windparken bij doorvaart. Wageningen University \& Research rapport C024/18; http://library.wur.nl/WebQuery/wurpubs/fulltext/446354.

Leopold M.F., Camphuysen C.J., Verdaat H., Dijkman E.M., Meesters H.W.G., Aarts G.M., Poot M. \& Fijn R. 2009. Local birds in and around the Offhore Wind Park Egmond aan Zee (OWEZ) (T-0 \& T-1). NoordzeeWind Report OWEZ_R_221_T1_20090605.

Leopold M.F., Dijkman E.M., Teal L. \& the OWEZ Team 2011. Local birds in and around the Offhore Wind Park Egmond aan Zee (OWEZ) (T-0 \& T-1, 2002-2010). NoordzeeWind Report OWEZ_R_221_T1_20111220_local_birds, IMARES report C187/11, 176p; http://edepot.wur.nl/191818.

Leopold M.F., van Bemmelen R.S.A. \& Zuur A.F. 2013. Responses of local birds to the offshore wind farms PAWP and OWEZ off the Dutch mainland coast. IMARES Report C151/12; http://edepot.wur.nl/279573.

Leopold M.F., Booman M., Collier M.P., Davaasuren N., Fijn R.C., Gyimesi A., de Jong J., Jongbloed R.H., Jonge Poerink B., Kleyheeg-Hartman J., Krijgsveld K.L., Lagerveld S., Lensink R., Poot M.J.M. van der Wal J.T. \& Scholl M. 2014. A first approach to deal with cumulative effects on birds and bats of offshore wind farms and other human activities in the Southern North Sea. IMARES Report C166/14; http://library.wur.nl/WebQuery/wurpubs/482985.

Lindeboom H.J., Kouwenhoven H.J., Bergman M.J.N., Bouma S., Brasseur S., Daan R., Fijn R.C., de Haan D., Dirksen S., van Hal R., Hille Ris Lambers R., ter Hofstede R., Krijgsveld K.L., Leopold M. \& Scheidat M. 2011. Short-term ecological effects of an offshore wind farm in the Dutch coastal zone; a compilation. Environ. Res. Lett. 6 (2011) 035101.

Skov H., Durinck J., Leopold M.F. \& Tasker M.L. 2007. A quantitative method for evaluating the importance of marine areas for conservation of birds. Biological Conservation 136: 362-371.

Skov H., Heinänen S., Lazcny M. \& Chudzinska M. 2016. Offshore Windfarm Eneco Luchterduinen. Ecological monitoring of seabirds, T1 report. Confidential Report, Project number 11813060, IfAÖ \& DHI for ENECO. 
Vanermen N., Stienen E.W.M., Onkelinx T., Courtens W. \& Van de walle M. 2011. Seabirds \& offshore wind farms: Power and impact analyses 2010. In: Degraer, S., Brabant, R., Rumes, B. (Eds), Offshore wind farms in the Belgian part of the North Sea: Selected findings from the baseline and targeted monitoring: 93-129. Royal Belgian Institute of Natural Sciences, Management Unit of the North Sea Mathematical Models, Marine ecosystem management unit.

Vanermen N., Onkelinx T., Courtens W., Van de walle M., Verstraete H. \& Stienen E.W.M. 2014. Seabird avoidance and attraction at an offshore wind farm in the Belgian part of the North Sea. Hydrobiologia: DOI 10.1007/s10750-014-2088-x.

Verdaat H. \& Leopold M. 2017. Work Method Statement. Wageningen Marine Research. WOZEP Vogels: Pilot Zeekoet. Document No.: WMS LUD 20170201_WOZEP-Vogels-Pilot-Zeekoet final.docx voor ENECO. 


\section{Justification}

Report C068/18

Project Number: 4315100084

The scientific quality of this report has been peer reviewed by a colleague scientist and a member of the Management Team of Wageningen Marine Research

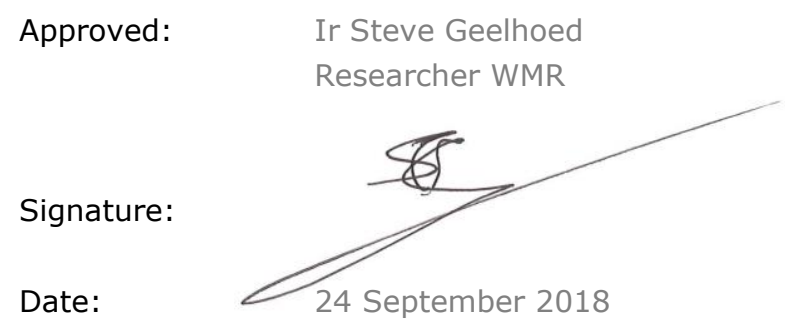
Approved:
Drs Jakob Asjes
Manager Integration
Signature:
Date:
24 September 2018 
Wageningen Marine Research

$\mathrm{T}+31(0) 317480900$

E: marine-research@wur.nl

www.wur.eu/marine-research

Visitors' address

- Ankerwind farm 271781 AG Den Helder

- Korringaweg 7, 4401 NT Yerseke

- Haringkade 1, 1976 CP IJmuiden
Wageningen Marine Research is the Netherlands research institute established to provide the scientific support that is essential for developing policies and innovation in respect of the marine environment, fishery activities, aquaculture and the maritime sector.

\section{Wageningen University \& Research:}

is specialised in the domain of healthy food and living environment.

\section{The Wageningen Marine Research vision}

'To explore the potential of marine nature to improve the quality of life'

\section{The Wageningen Marine Research mission}

- To conduct research with the aim of acquiring knowledge and offering advice on the sustainable management and use of marine and coastal areas.

- Wageningen Marine Research is an independent, leading scientific research institute

Wageningen Marine Research is part of the international knowledge organisation Wageningen UR (University \& Research centre). Within Wageningen UR, nine specialised research institutes of the Stichting Wageningen Research Foundation have joined forces with Wageningen University to help answer the most important questions in the domain of healthy food and living environment. 